scholarship in science and technology should be recognized as a federal responsibility, the Administration has been shillyshallying. Agencies such as the National Science Foundation have not helped by their trendy eagerness to be more relevant, whatever that may mean. What is needed now is some mechanism by which the Administration's responsibilities for basic research can be made distinct from its other responsibilities. It is hard to see how this can be accomplished unless there is a strong coordinating body which includes the directors of the National Science Foundation and of the NIH, the research directors of the executive agencies at present supporting basic research and a strong representation from the universities.

It is also clear that the Administration is desperately in need of some means of making sense of its hitherto incoherent policies on technology. Like other governments, it has set its heart on finding means by which public expenditure can be used to stimulate industrial innovation in the civil field and to yield results of social benefit. Like other governments, it has so far failed. The difficulty has been that governments, advised by thoughtless people such as $\mathrm{Mr}$ William $\mathrm{H}$. Magruder, have specified grand objectives and have then hoped that technologists will wave some magic wand to make cities decent, surface transport innocuous and earthquakes go away. The truth is, however, that in technology as in science, progress depends on the accumulation of small innovations whose ultimate uses cannot easily be predicted. What the American government needs is a mechanism for using the many public laboratories in the United States for maintaining a detailed watch on developments in their field of competence, for seizing new opportunities and for spending what money the government can afford. The Federal Council on Science and Technology, not a very useful body, could well be replaced by some device for controlling these activities and making sure they are sensibly directed. But here again, the Administration will have to acknowledge that it cannot make policy on its own.

\section{Trouble in the Loch}

WhateVER the final outcome of the application by the Gas Council and the Total Oil Company to build a gas terminal at Crimond airport in Scotland, there are lessons to be learned - and which should have been learned a long time ago. The first thing to be said is that the application, which involves the construction of a gas processing plant on the shores of Loch Strathbeg, concerns a scientifically important site with important physical and aquatic features (see page 80 and Nature, 240, 435; 1972). The second is that the terminal must be built somewhere. Britain needs North Sea gas and Scotland needs the jobs. That said, however, questions remain about the choice of site and, more important, about the way in which the provisional choice has been made public.

The site is clearly important. The Nature Conservancy says so, the Royal Society for the Protection of Birds says so and the opponents of the scheme, including Professor V. C. Wynne-Edwards, former chairman of the Natural Environment Research Council, are men of calibre, unlikely to get excited about nothing. Yet in spite of the importance of the site-and it would be naive to pretend that the Gas Council was unaware of its value-the first the Nature Conservancy officially heard of the terminal was when the Aberdeen County Council advertised on December 5 for objections to reach it within a fortnight. The conservancy, and other interested bodies, were therefore given two weeks to produce a scientific defence of a scientific site. Two months might have been more fitting.

Might not the Gas Council and Total have been somewhat freer with information about the scheme? The council says that the application was only for outline planning permission but this is a nonsense. How is it possible to tell what damage will be done until full details of the scheme are known and the likely effect on the loch accurately assessed? Similarly, Total's refusal to comment on the proposal before it went to the planning committee does not exactly encourage faith in the assumption that all other sites have been examined and that full account has been taken of the effect of the terminal on the loch. As things have turned out, Aberdeen County Council has had the good sense to postpone a decision on planning permission until fuller details are available and until the conservationists' objections can be better heard. The Gas Council and Total have this week been meeting the county council's countryside committee. Yet both the sponsors of the scheme could have saved themselves the trouble of ducking the mud thrown at them since the scheme was announced if only they had had the sense to consult other interested parties in advance.

As things are, if Crimond proves to be the only practicable site, the Gas Council and Total will have to live with the considerable hostility engendered by their handling of the matter. If some other site is finally chosen, they will somehow have to moderate the considerable distrust of conservationists in the industry's ability to consider interests other than its own. A little consultation early in the day could have saved the Gas Council and Total considerable time and effort (particularly if an inquiry holds up the application for months), and would also have avoided yet another head-on clash between conservationists and developers. Surely that is not too much to ask.

\section{Yeurs Ago}

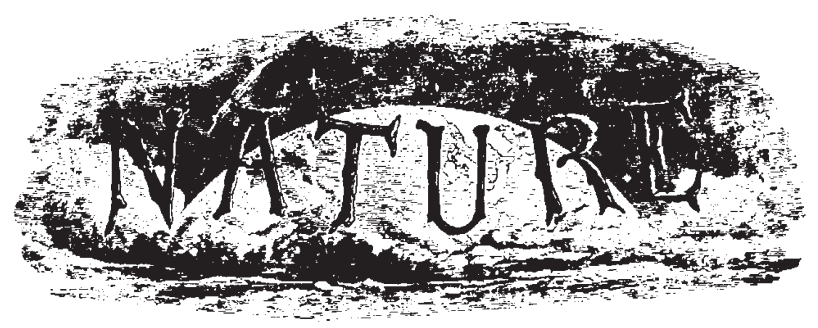

THв Octopus in the Brighton Aquarium met with a sad fate on Jan. 7. Finding himself uncomfortable in a tank where he had been newly placed by the curator, he cane out, in an un. guarded moment, of the house of living oysters he had collected as a shelter round him. In this tank were several large speci. mens of spotted dog-fish. One of these fish, with the true 'cute. ness of a sea-uug, immediately pounced upon the unsuspecting octopus, and swallowed him.--Another novelty has been intro. duced into the Brighton Aquarium, viz, the apparaius for carry. Ing on salmon and trout hatching. The tront from the Trent are thriving splendidly.

From Nature, 7, 209, January 16, 1873. 